\title{
IX. On the system of forces
}

\section{J.C. Delametherie}

To cite this article: J.C. Delametherie (1798) IX. On the system of forces, Philosophical Magazine Series 1, 2:7, 277-282, DOI: 10.1080/14786449808676919

To link to this article: http://dx.doi.org/10.1080/14786449808676919

$$
\text { 曲 Published online: } 18 \text { May } 2009 .
$$

Submit your article to this journal 준

LII Article views: 3

Q View related articles $\asymp$ 
upon any fortuitous circumftances. As I have fince learned from two well-informed naturalifts, that it was commonly believed that the garden fpider merely fuffered its threads to float in the wind by chance, I thought it might be of fome utility to publin the refult of my obfervations.

IX. On tbe Syjtem of Forces. By J. C. Dela methiRIE. From Journal de Phyfique, Brumaire, An VII.

GEOMETRICIANS, accuftomed to precife mathematical demonftration, cannot reconcile themfelves to the difficulties which occur in the explanations given by phyfics to the different phenomena of nature. They prefer the method of the great Newton, which is, to calculate the effects whatever may be the caufes; and hence has been introduced the fyftem of forces, which feems to gain ground in a fingular manner. Kant is one of the firft who announced it in Germany. He diftinguines two kinds of phyfics, the dynamic and atomift. He calls atomift phyfics that which teaches that the primitive parts of matter are compofed of atoms or indivifible parts, and which endeavours to explain all the phenomena of nature by the action or impulfe of different fluids. The fecond, which he calls dynamic phyfics, appears to him preferable. It fuppofes matter to be compofed of moleculæ always divifible. This matter is actuated by two forces: rit. the attractive; and, $2 \mathrm{~d}$. the repulfive. The atomifts confider fluids as compofed of fmall folid moleculæ. Kant does not admit thefe folid molecula. Fluids, according to him, are fuch originally, fo that we cannot conceive a part of a fuid which is not fluid. Thefe two forces, according to Kant, produce feveral other forces, viz. $3 \mathrm{~d}$, the caloric force, which is the principle of heat and of all the phenomena afcribed to fire; $4^{\text {th }}$, the luminous force, which is the principle of light and all the phenomena depending on it ; $5^{\text {th }}$, the electric force, which is the caufe of all the phe- 
nomena afcribed to electricity; 6 th, the magnetic force, which produces all the phenomena arcribed to magnetifm. Confequently all the phenomena of heat, light, electricity, magnetifm, according to him, are modifications of the attractive and repulfive force of the firt parts of matter, and there exifts neither caloric fluid, luminous fluid, electric fluid, nor magnetic fluid. This fyftem has numerous partifans in Germany, and it has even been extended fill further. 7 th. The galvanic force. Humboldt fuppofes that the phenomena of galvanifin may be explained by a particular force, which he calls the galvanic. Humboldt however always fpeaks of a galvanic fuid, as feveral of Kant's pupils fpeak of the caloric fluid, the luminous fluid, the electric fluid, and the magnetic fluid. But thefe are mere denominations, which exprefs the unknown caufes of the phenomena of heat, light, electricity, magnetifm and galvanifm. 8th. The vital force, vita propria. Blumenbach, to exprefs the phenomena of vitality, fuppofes a particular force, which he calls vita propria. $9^{\text {th. }}$ Nifids formativus. The fame learned man, to exprefs the formation of organized bodies, fuppofes a particular force, which he calls nifus formativus. This amounts to the fame as that called by other philofophers the plaftic force.

Birthez believes alfo, that we ought to confider all the vital functions in man and animals, as produced by peculiar forces and directed according to the primordial laws of a vital principle. "I think I have found, adds he, that there exifts in the living mufcles a force of the fixed fituation of the molecula and of their fibres (tending to reft) different from the forces of contraction and dilatation (tending to motion), the exiftence of which has not been before fo much as fufpected. The forces of the vital principle are inherent in each part of the body which they animate, and exercife there the movements peculiar to that part. The found method of philofophifing in each natural fcience admits in them general occult caufes*.

- Nouvelle Mécanique des Mouvemens del'Homme, par Barthez. 
As this expreffion, occult caufes, which modern philofophy has had fo much difficulty to banilh, is inconfiftent with the generally adopted ideas, I thall here offer fome reflections on that fubject, as well as on Kant's fyltem of forces. In my opinion, the manner of cultivating natural philofophy ought to be confidered under feveral points of view. Ift. Some confine themfelves to a defcription of the objects and phenomena that occur. The zoologift defcribes animals, their manner of living, and of reproducing their fpecies. The botanift does the fame in regard to plants. The mineralogift in the like manner defcribes minerals and their external qualities. The phyfical geographer defcribes the furface of the earth; and the aftronomer the celeftial bodies, their movements, \&c. 2d. Others go ftill further. The anatomift explores the internal parts of animals and vegetables, and defcribes their ftructure; and the chemift analyzes them, as well as minerals, to difcover the principles of which they are formed. 3 d. The geonetrician calculates the movements and forces of all thefe bcings, independently of the caufes by which they may be produced; and he fur, nithes the mechanift with calculations for conftructing and

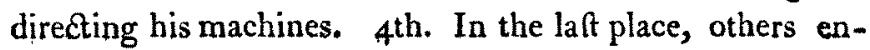
deavour to difcover the caufes of all the phenomena exhibited by thefe bodies, as well as to explain the mechanifm of their different movements. This is the fcience of phyfics. But it has fo often led men into error, that true philofophers are exceedingly difficult in regard to the explanations it gives. This has induced them to have recourfe to the fyftem of forces, by which they exprefs a fact, the effects of which they calculate without attempting to trace them to their caufes : as they cannot, for example, yest explain the phenomena of vitality, they exprefs them by the words vital force, whatever may be their caufe. The vital force, then, is that which produces the phenomena of vitality; but we are ignorant of the manner in which it acts. This is what ought to be underftood by the expreffion occult caufes. The an- 
cients, for example, not being acquainted with the weight of the atmofphere, could not explain why water did not rife in a pump but to a certain height. They faid it was the effect of an occult caufe; that is to fay, of a caufe with which they were unacquainted, which was concealed from them, occulta.

In the like manner we ought only to underftand by the word force the caufe of a general fact, whether this caufe be known or not. This is the acceptation in which the word was underftood by Newton. He obferved that all bodies had a tendency towards each other, and he called the caufe of this general phenomenon attractive force, or attraction. He obferved allo, that in certain circumftances they repelled each other; and he called the caufe of this fecond general phenomenon repulfive force, or repulfion. This mode of expreffion may be applied to all the grand phenomena of nature, and we may ufe the word force in the following differcut fenfes: Luminous force, the caufe of the phenomena of light; the caleric force, the caufe of the phenomena of heat; the elearic force, the caufe of the phenomena of electricity; the magnetic force, the caufe of the phenomena of magnetifm ; the galvanic force, the caufe of the phenomena of galvanifin; the fonorus force, the caufe of the phenomena of found; the capillary force, the caufe of the phenomena of capillary attraction; the force of affinities, the caufe of the phenumena of affinity; the diffolving force, the caufe of the phenomena of folution; the confolidating (folidifiante) force, the caufe of the phenomena of folidity; the cryftallizing force, the caule of the phenomena of cryftallization; the vital force, the caufe of the life of animals and vegetables; the generative force, the caufe of the generation of animals and vegetables; the nutritiof force, the caufe of nutrition; the mufcular force, the caufe of mufcular motion; the fympatbetic force, the caufe of fympathetic movements ; the concocing force, the capfe which affimilates morbific humours. The number of thefe forces might be greatly extended if we 
cmploy that term to exprefs the caufe of a general phenomenon.

The geometer calculates the effects of thofe forces which he employs, as he does algebraic figns inftead of numbers to fimplify his operations; but if he wilhes afterwards to obtain refults, he muft give to thefe figns their real values. In the like manner, if he withes to have a phyfical relult, he muft affign a value to the word force which he employs, The philofopher endeavours to difcover the caufes of thefe forces; but he is fo often deceived, and gives fo many falle explanations, that we are always inclined to confider as bad thofe which he alligns. We muft not, however, fall into the oppofite excefs, and afcribe to the word force an acceptation which it ought not to have. Let us imitate the wifdom of Newton: "All bodies, fays he, have a tendency towards each other; that tendency I call attraction, attractive force; but it may be the effect of an impulfion, or of fome other caufe which is unknown to us." He fays the fame thing of repulfive force. Let us apply this to all the forces before mentioned. The fonorous force, for example, has certainly as its caufe fome agitation in the fonorous body, and the atmofpheric air by which it is furrounded. This is a certain faet, though we cannot yet explain all the phenomena exhibited by fonorous bodies. The cafe is the fame with the luminous, electric, magnetic, caloric, and galvanic forces. The phenomena of heat, light, electricity, magnetifm, galvanifm, have as caufes the movements of particular fluids; and, though we are not yet able to determine the nature of all the movements of thefe fuids, we know that their action is in the inverfe ratio of the fquares of the diftances.

Reil has thown that the nifus formativus of Blumenbach ought to be confidered, as I have faid, as a real force of cryftallization. In general the formation of organifed bodies, their increment, their nutrition, is nothing but this force of cryftallization. It has formed all minerals; the globe itfelf, and the whole univerfe. It is alfo the confolidating 
2Sz Obfervations on the Satellites of the Georgium Planet, dating power, or that which gives folidity to all bodies. The force of cryftallization is confequently a force which acts in the moft general manner in nature; that is to fay, among exifting beings. Attraction itfelf is the effect of the action of the gravific fluid, and repulfion is the effect of the repulfive fluid or caloric. The philofopher acknowledges that he is yet ignorant of the manner in which all thefe fluids act : he is only acquainted with fome of their laws.

This acceptation of the word force leaves every poffible latitude to the calculations of geometry (which form the phyfico-mathematical fciences), and does not violate the principles of found philofophy. The expreffion oecult caufes, explained in this manner, can give no offence. But if people thould perfift to confider force as a quality independent of the action of all matter, fluid or not fluid, this would be a mere metaphyfical abftraction.

X. Obfervations on the Satellites of the Georgium Planet, and the two innermo/t Satellites of Saturn. By Dr. J. H. Sch roter, F. R. S. \&ீc. From Neuere Beytrage zur Enweiterung der Sternkunde. $\quad 1798$.

I WAS prevented by various fpeculations, during the hours. of obfervation, from directing the thirteen or twenty-feven feet reflectors to the Georgium Sidus till the igth of February $\mathrm{I} 797$, when about eight o'clock in the evening I looked at it through the thirteen feet reflector, with a magnifying power of almoft 200. It appeared very plainly as a planet of menfurable diameter, having a pale white light; and in a little time, when the eye became accuftomed to the inftru. ment, feveral very fmall ftars were perceptible around it. Two of thefe, being the neareft, in $a$ and $b$ (Plate VI, fig. $x$ ), were a little clearer, though it was with fome difficulty they could be diftinguifhed. The largeft, $a$, was to the 